Organization Science Vol. 12, No. 6, pp. 744-758.

\title{
Capabilities as Real Options
}

\author{
Bruce Kogut \\ Wharton School, University of Pennsylvania \\ (Phone: 215-898-1093, Fax: 215-898-0401, e-mail: kogut@wharton.upenn.edu) \\ and \\ Nalin Kulatilaka \\ School of Management, 595 Commonwealth Avenue, Boston University \\ (Phone: 617-353-4603, Fax: 617-353-6667, e-mail: nalink@bu.edu)
}

Revised April 2001

We would like to thank Ned Bowman, Carliss Baldwin, Howard Kunreuther, and Arie Lewin for many helpful discussions, the anonymous referees for their comments, and managers of Lucent for a reality check on some ideas. 


\begin{abstract}
Strategy research consists of a balance between positive and normative theory. Normative theories suggest particular heuristics, or cognitive representations, to find appropriate solutions. Heuristics permit faster solutions to real-time problems; they also suffer from the potential of negative transfer to inappropriate applications.

The theory of real options provides an appropriate heuristic framing of competencies and exploratory search. A real options approach marries the theory of financial options to foundational ideas in strategy, organizational theory, and complex systems. We join these approaches to identify three pairs of concepts: scarce factor and the underlying asset in option theory, inertia and irreversibility, and the ruggedness of landscape and option values. Strategic theories of resources largely define a core competence as unique and non-immutable. In doing so, this definition has wrongly forgotten Barney's initial insight into scarce factor markets as determining the valuation of a competitive asset. Financial theory of real options derives its heuristics of investing in exploratory search by inferring future value of today's investments from market prices.

We apply the three conceptual pairs to the evaluation of capabilities as real options through a formal descriptive model. The valuation of core capabilities is derived from observing the price dynamics of correlated strategic factors in the market. Because of inertia, managers cannot easily adjust the wrong set of organizational capabilities to the emergence of market opportunities. However, firms that have made investments in capabilities appropriate to these opportunities are able to respond. From this description, we define core competence as the choice of capabilities that permits the firm to make the best response to market opportunities. The heuristic framing of capabilities as real options guides the normative evaluation of the balance between exploitation and exploration.
\end{abstract}

[Key words: strategy, options, capabilities, heuristics, irreversibility, complexity] 
Strategizing is the application of heuristic frames to analyze the world and to generate normative evaluations of potential avenues of implementation. Strategy research reflects competing ideas about how the world looks, or what the world needs. However, like their counterparts in engineering or architecture, strategy researchers distinguish themselves from practitioners by their attention to an articulation of theory and evidence. It is this serious concern for the design of practice by an investigation of the appropriate theoretical framing that is the mark of applied sciences in professional schools (Simon, 1969).

There is currently debate in strategy research between the importance for a firm to "position" itself in the market or to focus on developing unique capabilities. Ned Bowman (1995) made the distinction between strategies that look in the mirror and those that look through the looking glass. In the parlance of contemporary strategy research, resource and knowledge theories of the firm are inward looking, whereas market positioning and industry analysis are outward looking.

It is not surprising that during a time of restructuring and re-engineering, strategy researchers should shift the emphasis from industry analysis to the internal sources of competitive advantage. The current emphasis on looking in the mirror begs the question of how to choose among alternatives. The resource based and knowledge theories view the unique capabilities of the firm as the cornerstone of sustainable rents. These approaches share the common insight that a chosen strategy presumes the capability of implementing the vision. A heuristic appropriate to identifying capabilities required to support a strategy is provided by the notion of core competence, as proposed by Hamel and Prahalad (1994). And yet, it is often overlooked that Hamel and Prahalad (1994) essentially invert the framing of a resource-based 
view of strategy by arguing for the analysis of white spaces in the market topography of existing businesses to identify valuable avenues of exploration.

The ideas of core competence and white spaces share strong parallels with the heuristic application of real option theory to strategy, whereby investments in exploration create capabilities to address future opportunities. A real option is the investment in physical assets, human competence, and organizational capabilities that provide the opportunity to respond to future contingent events. A good example of a real option is the investment in a sales operation in a developing country that loses money but provides learning of the environment that will provide the future capability to expand if the country should grow. Firms, as adaptive systems, strike a balance between refinements of existing processes and explorations of variations on new techniques and new markets.

In this regard, a real option is strongly reminiscent of the distinction between exploitation and exploration (Hedlund and Rolander, 1990; March, 1991). The static analysis of deciding to allocate effort to each of these activities is especially complicated, because current efforts result in short-term efficiencies that can overwhelm long-term efforts of exploration. Yet, if firms and their environment are engaged in a co-evolutionary dynamic, then it is useful for a firm to ponder the match between its future capabilities and future environments. This firm to environment coevolution is coupled in turn to the co-evolution of capabilities within the firm. Thus, the dynamics by which capabilities interact and are learned pose a complex combinatorial problem.

Organizational theory has been slow to embrace the idea that organizations can proactively exploit risk, rather than just absorb it. We propose that the theory of real options provides an appropriate theoretical foundation for the heuristic frames to identify and value 
capabilities and exploratory activities. Since capabilities are platforms that create a generic set of resources, they represent investments in future opportunities (Kogut and Kulatilaka, 1994). In effect, real option valuation marries the resource-based view with industry positioning by disciplining the analysis of the value of capabilities by a market test.

We proceed by first characterizing the value and limitations of heuristics. We then develop the use of real options as a heuristic and show how it is grounded in, and throws light, on three lines of thought of strategy: resource based view of the firm, traditional organizational theory, and complex adaptive systems. A central concept in organizational theory is inertia. Its allied notion in financial economics of "irreversibility" is critical to the definition of a real option. The argument that we develop is that capabilities reflect irreversible investments, because of the costliness of rapidly transforming the organizational knowledge in a firm. This knowledge is composed of the set of technological and organizational complements, very much in the spirit of the socio-technical tradition. The difficulty facing a firm is that improvements in complements provide a competitive advantage, while also generating a high level of inertia that inhibits the firm from radical change.

We examine these ideas through a stylized mathematical description of the problem of adopting radical change. Our formalization clarifies that the benefit of a real options heuristic is the imposition of a market test to derive the valuation of capabilities. It also allows for a precise definition of a core competence as derived from the valuation of inert resources given the environment.

\section{Strategy as Heuristics:}

Following distinctions made in cognitive science, we separate a heuristic into its 
cognitive frame and the rules of search. A cognitive (or heuristic) frame refers to the 'representation' of the problem and solution space. The heuristic rules of search are the algorithms by which solutions are found in the represented solution space. ${ }^{1}$

Simon (1969) introduced both of these elements by defining heuristics as procedural search in distinction to the substantive rationality of economics and operations research. Simon noted that the solutions to many problems are not computable, that is, the search algorithm cannot in finite time determine the optimal answer. The problem of computation is classically illustrated by the traveling salesman problem in which the objective is to minimize the travel costs of a salesperson who has to visit 50 cities. The 50! calculation is computable, but not within any reasonable horizon. For this reason, many heuristic algorithms have been proposed to provide "satisfactory" but not clearly optimal solutions to this problem.

Strategy often has this level of complexity and also often lacks a method of determining the optimal choice. In order to know whether a firm should enter into a particular business, it is important to understand the costs and quality of the product or service that can be delivered. It is also important, consequently, to understand the response of competitors to the competitive entry of an innovation and its embedded bundle of attributes (e.g. price, quality). There are, then, two embedded decisions, one determining the capabilities, the other the market strategy. The dimensional problem of identifying all these elements and understanding their interactions quickly defies a declarative analysis (i.e. net present value) or an exhaustive procedural search across all combinations.

Heuristics have the advantage of countering some cognitive biases, but at a cost. In some

\footnotetext{
${ }^{1}$ See Minsky (1985:74, 243-253) for an example.
} 
cases, the heuristic will lead to non-optimal decisions. In a study on plant scheduling, Bowman (1963) found that managers would do better if they used linear estimates from their experience rather than tried to optimize in response to each situation. The implication is that managers would do better to rely upon experiential heuristics than seek to optimize each situation. In real time, the search for optimal strategies can be too costly or liable to be influenced by recency effects (e.g. the arrival of new information). Kunreuther (1969) modified these findings that rules cued to selective environmental information improve actual decision-making. This finding implies that there may be certain meta-heuristics that identify the environment and, thereby, indicate the application of less robust but more appropriate decision rules.

One of the merits of a heuristic is its real-time utility. One of the cornerstones of evolutionary organizational theory is March and Simon's (1958) notion of routines, which is an organizational enactment of heuristic problem solving. (See Nelson and Winter, 1982.) Studies on innovation show remarkable tradeoffs between costs and time for innovations (Scherer, 1967; Mansfield, 1988; see Midler's, 1993, discussion). Consequently, because the development and use of heuristics are situated in particular contexts that are only partially understood, they can be misapplied.

The Cohen and Bacdayan (1994) experiments illustrate these tradeoffs between routines as heuristics and misapplications. Their study of the emergent rules in a simple card game showed that simple heuristics routines guided the behavior of play. Better routines, of course, were associated with better outcomes. When the game changed, the players tended to engage in "negative transfer," that is, they transferred the acquired heuristics to the new game even though inappropriate. 
Strategizing is, then, the application of imperfect heuristics to problem solving and implementation. Unlike the implicit heuristics that represent what Argyris and Schoen (1978) call "theories in use," formal strategizing applies explicit "espoused" schemas to search for appropriate decisions. Nevertheless, the underlying theories to these heuristics are often only implicit. Even explicit heuristics are liable to be applied to the inappropriate setting if hidden assumptions prove to be wrong. Since complex interactions mark organizational choice, the potential for the cognitive misrepresentation of the problem is large. Thus, an important feature of any framework is a process of discovery and experimentation.

It is this process that the heuristic of real options attempts to impose and evaluate. It is also theoretically the resolution to the conflicts between organizational theories of inertia and change. We address first the heuristic value of real options and then turn to the theoretical implications.

\section{Strategy and Real Options:}

The core competence concept arose in the late 1980s during the height of re-engineering propelled by acquisitions and new information technologies. It is a direct response to the reputed financial pressures from financial markets dominated for the first time by institutional investors. The formulation by Hamel and Prahalad (1994) suggests that the initial data are in the spirit of understanding the intended strategy of the firm that should be grounded in a distinctive competence, an idea that dates back to Selznick (1957).

The theoretical foundations to this view are several, from the reasoning about why knowledge is hard to imitate to the evolutionary theories of firm growth. From a decision theoretic perspective, the core competence framing lends itself readily to a real option 
interpretation. A real option is technically defined by an investment decision that is characterized by uncertainty, the provision of future managerial discretion to exercise at the appropriate time, and irreversibility.

These three elements are jointly required for the application of a real options heuristic. An option has value only if there is uncertainty, though defining the relevant source of the uncertainty is not trivial. An operationally important element of design is the provision of discretion, such as the staging of an R\&D project to correspond to discrete points of go-no go decisions.

Irreversibility is an easily overlooked feature and signifies the change in future possibilities due to a decision taken today. Irreversibility is a subtle idea that carries the notion of the arrow of time. ${ }^{2}$ For example, the decision to pump oil means there is less oil in the future today; hence the economics of non-renewable resources are different than those of producing paper clips.

The concept of irreversibility is critical to why inertia of organizational capabilities is the source of the value of real options. Because time has an arrow, the decision to delay making investments in knowledge needed to enter a new market has a time subscript. The value of this decision will be different if it is considered next year; other firms may have entered and the early rents are now dissipated. Since strategy entails a decision to invest in capabilities in order to sustain a market strategy, foregoing this investment means that the firm does not have the option to launch the strategy if the market becomes favorable. However, not all capabilities are

\footnotetext{
${ }^{2}$ Georgescu-Roegen (1971: 196ff.) provides an explicit and early discussion of irreversibility, hysteresis (as discussed later), and the arrow of time. A useful paper is Henry (1974). The arrow of time and evolution are central themes in Prigogine and Stengers (1984). A volume of essays on irreversibility is Boyer, Chavance, and Godard
} 
irreversible. The failure of a firm to invest in information technologies at one point of time does not preclude contracting for such services in the future. More likely, the opportunity to invest diminishes over time, as others come to acquire the necessary capabilities. There is, therefore, a time dimension between making a decision to invest and its actual implementation during which the value of the investment will change.

Irreversibility implies that the asset should be "scarce" and difficult to replicate in a timely way in order to support a strategy at a particular time. If, through imitation and substitution, this factor will be more abundant in the future and its value will be less, the option value is only realized through the current investment to exploit transient opportunities. ${ }^{3}$ A core competence is indeed Barney's scarce factor, because it embeds complex options on future opportunities. It is odd, and unfortunate, that the importance of market opportunities to derive valuations of this scarce factor was lost in the rush to emphasize only resources. In the early resource description, Barney (1986) relies on market valuations to back into his identification of unique assets. But he ignores that scarcity, or irreversibility, implies that value depends upon guesses about future use.

Dierickx and Cool (1989) note exactly this point that Barney makes the incomplete inference by ignoring irreversibility. When assets are irreversible, firms must have differential resources because of the arrow of time (or what they call "time compression"). Because it takes time to build and absorb capabilities, a firm cannot spontaneously replicate scarce assets. Consequently, some firms will discover profitable projects, where the 'excess rents' are earned

(1991).

${ }^{3}$ For a discussion, see Kogut and Zander (1992) on knowledge and combinative capabilities as options, and Zander and Kogut (1995) and Szulanski (1995) for empirical studies that measure inimitable as tacitness. 
through their organizational complementarities, not through superior information.

This conclusion emphasizes that the scarcity of core competence should be reflected in equilibrium financial prices, even if a firm cannot earn excess rents by buying this competence in the market. This point corresponds to Barney's contention that a market for scarce factors forces external prices to reflect the present and future value of the internal assets. The market attempts to value the scarcity of these assets for generating current and future cash flows given a firm's position in the market. In other words, scarcity itself does not determine the value of a competence. It is a necessary but not sufficient condition. Rather, scarcity is interesting if the competence permits a firm to achieve a competitive position in the market place. If this is not true, then scarcity could simply be the unique capability to produce bad ideas. Somehow, the market has to matter.

To keep this simple, let's return to the example of drilling oil. The oil is a finite and scarce resource. The decision to pump is influenced by today's price and by guesses regarding future prices. To pump today means less oil to pump tomorrow, an irreversible decision. If suddenly a new energy technology reduces beliefs about future demand, the value of the scarce and non-renewable oil declines. But this "exogenous" price change is the competitive decision of a rival to introduce a new technology. What is this firm's incentive and capability to innovate and to implement? To answer this question, one needs to understand the position of firms in the industry.

Some writers fail to make this observation altogether. For example, Teece, Pisano, and Shuen write that "core competences must accordingly be derived by looking across the range of a firm's (and its competitors) products and services" (1997: 516). This statement is, however, 
seriously incomplete. The missing element in this analysis is, of course, Barney's scarce factor market. A firm may be well endowed with patents making it difficult for competitors to imitate. However, the important question is whether these endowments, which we might also call more generically the knowledge of the firm, is useful not only to current, but also to future applications. This question is not answered by a notion of dynamic capabilities, or what Kogut and Zander (1992) called combinative capabilities in the absence of understanding the market. Teece, Pisano, and Shuen fail to realize that their appeal to "path dependence" is indeed a "forward path" as well. If you know the future is dependent on the present -there is irreversibility, then it is worthwhile to think about this path too. When the object of this path is defined (e.g. profits, prices, costs), then it is inevitable that one thinks about the market and the position of the firm. This objection is not petty, for it is easy to imagine that without market discipline on the analysis, the potential candidates for core competence quickly multiply. It is rare for managers to characterize their competence, and their divisions, as peripheral.

There is another way to think about this problem, suggested by Winter (1987), as a broader formulation along the lines of optimal control. Winter (1987: 180-181) states, "From evolutionary theory comes the idea that a state description may include organizational behavioral patterns or routines that are not amenable to rapid change, as well as...more conventionally defined assets. It is by this route that a variety of considerations that fall under the rubrics knowledge and competence may enter the strategic state description. ${ }^{4}$ Conventionally, optimal control describes the state characteristics of the environment and allows the decision maker

\footnotetext{
${ }^{4}$ Winter (1987) suggests net present value as a measure, which is appropriate for the case without uncertainty. Most surveys on the use of capital budgeting techniques show that almost all large corporate firms use net present value calculations for investment decisions. See Kogut and Kulatilaka (1992) and Baldwin and Clark (1992, 1994) for a discussion why investment in capabilities is not a net present value of cash flows but a real option valuation.
} 
discretion over a few control variables, e.g. technologies or output. Winter's suggestion is to capture the constraints and opportunities of capabilities through a richer description of the state variables and their evolution over time. This is their future path, no matter how constrained by history. It is this insight that we use below in our formal treatment.

\section{The Organizational Ecology of Irreversible Investments}

The idea that value is created through building capabilities to provide the option to exercise discretion runs counter to a considerable body of organizational theory. This tradition has been challenged in recent years by notions of "adaptation." But there has not been a thorough rethinking of these issues. We make the claim that in fact adaptation is not interesting without a concept of inertia (e.g. irreversibility), and inertia is valuable because it implies capabilities are scarce.

Organizational theory historically has viewed uncertainty as threatening the stability of the technical core of an organization. By proposing the idea of "uncertainty avoidance," March and Simon (1958) suggested that an organization's design serves the function of eliminating variance. This idea appears also in Thompson's (1967) landmark book that analyzes the many ways that firms buffer themselves from uncertainty. Similarly, Pfeffer and Salancik (1978) motivate the theory of resource dependency as the creation of organizational mechanisms to reduce uncertainty

The contribution of organizational ecology is to formulate more explicitly the relationship between environmental uncertainty and organizational strategies in a dynamic setting. In particular, Hannan and Freeman (1977) distinguish between environments that change smoothly from those whose change is granular, i.e. more abrupt. This distinction between two kinds of 
uncertainty -a distinction that we exploit mathematically below- implies that in granular and uncertain environments, generalists will do better than specialists. This notion of generalists is defined operationally in their empirical work as organizations whose competence corresponds to a broad array of possible environmental outcomes.

Organizational ecology and adaptation as "path dependent options” enjoy considerable affinity, once the assumption that generalists and specialists are exogenously given is dropped. Would it not be reasonable to see firms adaptively investing in these capabilities in response to the granularity of their environments? They look forward, they evaluate the inertia and irreversibility of their positions, and they gravitate toward degrees of discretion depending upon their assessment of their environmental uncertainty. Consider the following thought experiment. Look at large multi-businesses today and ask how many started as specialists in a single business? How many specialists today were born as multi-businesses? It would seem that the experiment is inherently biased toward finding an asymmetry expressed along the diagonal. That is, specialists become multi-businesses with some non-trivial probability, but few multibusinesses gravitate towards specialism. Growth is adaptive search.

Given its stress on inertia, it is not surprising that organizational ecology implies an option formulation of the growth path. In the framing of options, generalists are organizations whose competencies are robust across many future states of the world, but the carrying cost of diversity carries a survival penalty. The formulation by Tuma and Hannan (1984) makes the analogy between options and survival strategies formally explicit. They note that a hazard model is the probability of hitting a lower boundary in a stochastic diffusion process that governs the growth of the organization. Indeed, the conditional probability of exercising the option is also 
the hazard of hitting the boundary of a diffusion process. The difference between the two approaches, of course, is that a real option model considers typically the upper boundary, that is, the probability of increasing growth by exercise rather than the implied strategy in organizational ecology of minimizing the hazard of death. ${ }^{5}$ The inertial qualities of an organization are consequently central to understanding the value of a firm's assets for future deployment given the uncertainty and graininess of the environment. Indeed, it is exactly because of McKelvey (1999) contention that the environment changes more rapidly than organizations, there is value in investing assets to respond to future changes.

Organization ecology, like organizational theory in general, has sought to separate out features of the organization that can be easily changed and hence peripheral from those that are inert and hence core. Following Thompson, the core has frequently been regarded as technical, a point of view also adopted by Scott (1995). It is not clear why this is a good assumption, and it begs a more explicit theory. Such a theory is evolving in the context of understanding “complements." In this inquiry, neither technology nor organizational design is given an a priori status as core, or inert. The source of inertia may well lie in their interaction, as opposed to their inherent property.

Core and periphery imply a dimension of distance. This notion of distance in core and periphery is one of the hardest concepts in organizational science, and yet is found also in the fundamental organizational concepts of local versus exploratory learning and radical or

\footnotetext{
${ }^{5}$ Howard Kunreuther points out to us that a strategy of minimizing death results in sub-optimal behavior, as shown in an extant literature in the decision sciences. Still, there is a technical correspondence between evaluating the value of the firm at either boundary. As Black and Scholes (1973) noted early in the development of option pricing, the boundary defined by bankruptcy can be used to value the stock. Note also Tuma and Hannan's acknowledgement of the non-linear and stochastic process that governs firm growth in their chapter 12 and 15 discussion of stochastic calculus.
} 
incremental innovation. These concepts share the idea that firms can be mapped onto a multidimensional space representing different combinations of technological and organizational practices. (In the next section, we turn to understanding this space as rugged.) To simplify these dimensions, consider a two dimensional space with the coordinates representing a combination of a technology and organizational practices. The notion of inertia poses the question of whether it is easier to move along the technological or organizational dimensions if one wants to change.

The organizational literature on innovation has implied that the technological dimension is especially problematic by emphasizing the difference between incremental and radical innovation. The dimension of organization appears as independent from this consideration. Tushman and Anderson (1986) have offered the insight that innovations can be characterized as radical or incremental depending upon whether they destroy or enhance a firm's competence. (See also Henderson, 1993.) This reasoning ultimately leads to the consideration that the radicalness of an innovation has less to do with the novelty of the technology than its conformity with existing knowledge of the firm, i.e. the ways by which work is organized and power is distributed. Since the way work is organized will vary by firms, then the radicalness of a technological innovation can not be determined independent of a particular organizational context. Switching, or adoption, costs are strongly contingent on the current organization of work.

One of the most perplexing questions in organizational behavior is the failure to identify clear matches between technologies and organizational structures. (See the review given in Dosi and Kogut (1993) and the summary of the work comparing U.S. and Japanese organizations in Lincoln, 1993.) Dosi and Kogut (1993) proposed that the failure to find robust relationships has 
been due to the tendency to theorize element to element correspondence, such as high volume production with vertical hierarchy. ${ }^{6}$ The empirical results do not show that these are complements when other factors are controlled. Alternatively, Dosi and Kogut suggest that the correspondence might be set to set, where a set of organizational practices maps onto a set of technologies. The data might not reveal that $\mathrm{A}$ and $\mathrm{B}$ exist as complements; all we observe is $\mathrm{A}$ and $\mathrm{C}$ and $\mathrm{D}$ and $\mathrm{B}$.

Complementarities need not be unique between any given technology or organization, but they still should be relationally bounded. The recent findings by MacDuffie (1996) on "bundles" of human resource practices in auto plants indicate that there is a logic that relates organizing practices to each other, and to technologies. The experience of General Motors and other car manufactures is that adopting the new capabilities of flexibility and speed requires changes in automation and organization. Between these two sets, there are many functionally equivalent complements, but there are no unique element-to-element correspondences.

This description captures also Dosi and Kogut's idea of co-evolution of technology and organization through two key features. First, technology and organization do not represent random assignments, nor is their coupling simply at the discretion of managers. Rather, the matches of a technology and organizing principle are constrained to reasonable set-to-set correspondence. However, within these 'developmental' constraints, improvements in technology and organization are correlated through experiential learning. For example, the introduction of mechanical equipment to move the chassis from one line to the next required the

\footnotetext{
${ }^{6}$ This point is explicit in the lattice formulation of Milgrom and Roberts (1990), where a firm's choice is constrained by technical complementarities. Kogut and Kulatilaka (1994 revised) discussed complements and the co-evolution of technical and organizational capabilities as a Kaufmann problem. See Levinthal (1997) and the discussion below.
} 
organizational innovation to increase the 'tightness' of the coupling of serial work processes in the factory. In other words, technology and organization are dynamically coupled in their evolution.

The costs of altering tightly coupled components of technology and organization imply that firms will persist in their old ways beyond the recommendation of the net present value. This persistence defines a range of inertia, or what is called a hysteresis band. Because organizational change is disruptive and hence discontinuous, managers hesitate to change radically their organizations, hoping perhaps that future states of the world would provide more appealing environments. Thus, contrary to the normative value in responding flexibly, inertia is rationally encouraged in highly volatile environments if change is costly and the environment is granular.

Figure 1 provides a simple illustration of this point. A firm can choose between two complementary systems, called low and high variety. The important issue is whether the relative value of gaining the capability of variety is enough to offset the costs of discontinuous change.

The choice of capabilities is, as we depict it, derived from the market price placed on variety. Because of uncertainty over the evolution of the value of variety and the costs of adoption, managers rationally might choose to persist with inferior techniques before they are confident of future developments. Inertia, then, is not simply a property of stickiness, but reflects expectations regarding the value and costs of change. Inertia increases with uncertainty, because managers are rationally hesitant to incur the cost of change to capabilities that may become easily worthless if the environment reverts to its previous state. (Clearly, inertia can also stem from considerations of loss aversion or status quo bias of managers.) 
In a normative vein, it stands to reason from the point of view of an organizational ecology that a firm should experiment in activities that promote its future survival (Lewin and Volderba, 1999). In this sense, organizational ecology offers an escape from the inward-looking bias of the resource-based view of strategy. For enhancing future survival, a firm should invest in platforms that correspond to expectations regarding the evolution of the external environment. Platforms are technological and organizational investments that permit a firm to enter into a wide menu of future markets. Firms that build general platforms are more likely to survive and grow (Kim and Kogut, 1996). It is exactly the evaluation of this correspondence between exploration of new capabilities and the evolution of the market environment that is provided by the application of a real options heuristic.

\section{Complex Adaptive Systems and Option Theory: ${ }^{7}$}

A hallmark feature of complex systems is the recognition that environmental change is marked by sharp non-linearity (Lewin and Volderba, 1999). An option is defined, of course, by returns that are non-linear and contingent on the stochastic state of the world. Hence, it is not surprising that option valuation is appropriate in complex and non-linear environments.

To avoid confusion, we distinguish between experimentation and market search. Search is the effort to identify new applications of products and services to new markets and landscapes. Experimentation is the learning of new techniques and combinations of technical and organizational elements. In practice, the market search and experimentation are likely to be linked and, consequently, it is confusing to insist too strongly on their separation. It is nevertheless useful to remember that new ways of doing things and addressing new markets are

\footnotetext{
${ }^{7}$ This section represents an elaboration as requested by Arie Lewin.
} 
not the same.

To understand what innovation stream to choose and what kinds of flexibility to develop requires an evaluation of the implications of experiments and market exploration for the contours of the innovative landscape. For this, we need to match more closely the stochasticity of the environment to experiments of new combinations of organizational and technological elements.

A landscape is the performance contour generated by the aggregation of each firm's position in a multi-dimensional space given by its configuration of resources. Without imposing a core and periphery, it represents distance among organizational and technical features in a multi-dimensional space. (If features are identified as 'there' or 'not there', then the measure of proximity is the Euclidean hamming distance in a multidimensional space.) The ruggedness of the landscape implies, much like the theory of strategic groups, that firms compete around discrete combinations of resources that correspond to different market niches, or that provide functionally equivalent methods of production. Moving from one to the other is problematic because competencies are scarce (that is, difficult to imitate) and also because a landscape coevolves through competitive interactions.

A useful heuristic in this kind of representation is to know the value of directional change in the landscape. The value of changing resources and hence changing position in this landscape requires an evaluation of the cost of change against the future unknown reward. This is what option theory does; it puts a value on the investment in the capability to change position in the landscape contingent on the environmental outcome. It does this by inferring from today's market valuations the expected value of changing position in the future. Unlike the fitness landscapes found in organizational ecology and biology, real options looks at the value of a 
position, where contours correspond to different valuations placed on the assets of an organization.

Complex adaptive system thinking has found it difficult to give heuristic advice other than the importance of creating a process by which to respond to uncertainty. In his thoughtful conclusion to a special issue on complexity, Cohen (1999: 375) concludes that aim of recent "efforts is not so much a theory that predicts what a given complex system will do, but rather a framework." However, ultimately, a framework needs to provide decision heuristics to evaluate choices.

The normative literature in organizational theory (e.g. Tushman and O'Reilly, 1997; Brown and Eisenhardt, 1998) has in recent years recognized the value of flexible responses to radical uncertainty as an organizational capability in complex environments. Brown and Eisenhardt (1998: 151) connect explicitly probes with options thinking. If the future evolution of opportunities was obvious, then a firm could focus the efforts of change in one direction. However, since the direction of change is unknown, it pays to invest in probing. But clearly, a heuristic to choose the probes is still required.

It is useful to marry the perspective of probes as options with the idea of a rugged landscape, an idea that originates in biology but that has useful applications to understanding the performance implications of complex interactions among complements. (See Kauffman, 1993; Levinthal, 1997; McKelvey, 1999.) Consider a firm that is located near a local peak. Holding its environment constant, probing consists of learning about superior ways to combine its technological and organizational elements. By learning, we imply a notion of knowledge that is incomplete and not entirely explicitly understood. It is incomplete, as suggested by the 
observation that firms innovate incrementally to improve existing practices. It is partly tacit; or else firms would easily converge to best practice. To return to the set-to-set discussion in Dosi and Kogut (1993), local learning is the discovery of the correspondence between new elements in the existing set of techniques.

The case of local learning is different than moving from one peak to another. Moving to a new peak implies an architectural change in the language of Henderson and Clark (1990). Such change is no longer experimentation around individual modules but requires a complex redesign around new sets of technical and organizational elements. Normally, radical architectural change is viewed as incurring catastrophic risks due, for example, a competitor's introduction of a product that requires a major change in a firm's capabilities. But in fact, such change can be orchestrated through search and experimentation that effectively builds ridges between peaks.

Baldwin and Clark (2000) propose a real options approach for understanding the choice of modules when performance outcomes are unknown. The explicit valuation of the activity of experimentation raises an important issue of the design of the firm. It would seem, arguably, that the best design for exploration is based on modularity, whereby a firm can pick and choose the best components. Since modules might be viewed as independent experiments, a reasonable inference is that the firm, like a market, should be designed around independent teams. This argument is, in fact, congruous with Simon's (1969) argument of the social decomposition of organizations into relatively independent units.

The heuristic framework of Baldwin and Clark cannot, however, be applied to the case of radical architectural change. This is no longer a mix and match problem of modules, but represents the switch from one conjoint set of technological and organizational correspondences 
to a new set. In this environment, a firm cannot exploit its path dependence. It rather must evaluate the distant contours of the value landscape and decide the optimal timing to switch new capabilities. As we will show, this problem is, in fact, less severe than commonly portrayed, because exploration permits the building of ridges between value peaks.

\section{A Formal Description}

To ground a heuristic of real options in positive theory, we have indicated the commonalties in strategy, organizational ecology, and complex systems by pairing three concepts of scarce factors and the underlying asset, irreversibility and inertia, and the landscape ruggedness and option values. To make these pairings explicit, we present below a formal description that grounds the heuristics of real options in organizational theory. We make use of the following three principal ideas. First, the inertia of organizational and technological combinations requires a notion of time, that is, of irreversibility as indicated by the dynamic market valuation of organizational assets. (There are, of course, start-up and transaction costs, which we incorporate into switching costs.) Second, that distance in discrete combinations results in a radical difference between learning and recombination of modules within a family of organization and technical elements as opposed to between families. Last, uncertainty can be decomposed into continuous and granular measures of change.

We seek below to offer the theoretical underpinnings to understanding capabilities as an option, not to value explicitly a real option. (Dixit and Pindyck (1994) and Amram and Kulatilaka (1999) provide a thorough collection of such applications.) For many applications, there exist reasonable avenues of valuation. The formal description has the important advantage of clearly defining a core competence in reference to a market valuation, as well as providing a 
clear statement of the tradeoffs between learning and exploitation, on the one hand, and experimentation and exploration on the other. The graphs, which are drawn based on linear profit functions and particular parameter values, illustrates these tradeoffs and switching points.

\section{Looking Out the Window: Market Prices}

We began with Bowman's observation that strategy looks outside the window, or into the mirror, and option formulations bridge the two. How then should we evaluate the strategic alternatives regarding the long-term development of internal capabilities? As we have argued, the value of a capability depends not only on the internal assets but also on how those assets are deployed and the external market conditions. Thus, the price of a correlated asset in the relevant 'scarce factor' market represents the initial point of departure. The value of a capability is then inferred from the observed price dynamics that replicate the payoff to the real option. This replication is the device through which market discipline is imposed on the identification and selection of core capabilities. It is not the static comparison of the capability and strategic factor that matters, but rather the information that is gleaned in the changes in prices over time.

To elucidate the intuition, consider again the framing of a real options problem. The organizational assets of a firm provide an option to spend a fixed amount to procure a new capability by purchasing a physical asset at the end of one year. If the option is exercised, then the resulting project value has the risk characteristics of an existing traded firm. For example, a pharmaceutical firm is considering an entry into biotechnology. It currently has a strong capability in conventional drug development that provides an option to enter into biotechnology at an estimated cost. This cost is idiosyncratic to this firm. However, once it enters into the market, its new business carries a market risk similar to other biotechnology firms. This example 
illustrates why the price of other firms does not give the value of the core capability, since the cost of entry is idiosyncratic to each firm. However, the price dynamics of other firms provide information on the factors (e.g. risk) that drive the value of the option to enter in this market.

The value of a financial option depends on the current share price. Since the source of this exogenous uncertainty is the market price of a frequently traded market financial security (the share of stock), financial options can be dynamically replicated with a portfolio of stocks and risk-free investments. As a result, derivatives can be valued without knowledge of the expected return earned by the underlying financial asset.

For a special but important case, Black, Merton, and Scholes derived this value through an option pricing formula. The simple, but critical, innovation was their eventual recognition that by composing a replicating portfolio, the value of the option could be perfectly tracked by a levered position in the traded stock. It is, however, unlikely that real options can be perfectly replicated with traded assets. The replication may require the use of product or factor prices. Even when widely traded, the prices of such real assets need not appreciate at a rate equal to its equilibrium risk adjusted return. Instead, owners of real assets will reap various convenience benefits and incur carrying costs that affect the total returns. In such cases, valuation requires knowledge of the actual price dynamics of the factor price and the equilibrium risk adjusted return.

As an initial proposal, we suggest that the theoretically most interesting way to identify the appropriate correlated asset is to decompose the market price into a bundle of attributes that pierces the revenue veil of the firm to see the underlying assets. Whereas this analysis is unquestionably hard, it should be recalled that it is consistent both with the financial market 
pressure to understand (i.e. strip) assets and the growth of derivatives to hedge specific components of a firm's risk. From this angle, the value of the capability depends on its contribution to the price of product or factor prices whose risk is spanned by traded assets in the economy. The value of the capability is, thus, obtained by explicitly specifying the profit function using these prices as an argument.

In order to identify and value a core competence, we must specify the evolution of the quality-adjusted price that we call, $\theta$. A simple example is a microprocessor, whereby a qualityadjusted price can be expressed as the ratio of price to the processing speed (or "mips" for millions of instructions per second). Since we cannot observe directly this price, we can choose the stock price of a firm specializing in microprocessors to give the estimates for the volatility. However, since $\theta$ is not a pure security but is the observed price of a scarce factor, its price characteristics need not necessarily evolve according to its equilibrium risk characteristics. Local supply and demand conditions and technological innovation determine the evolution of $\theta$. We want to sort out smoothly evolving uncertainty from discrete granular shocks. We assume $\theta$ to be exogenously determined and characterize its evolution by stochastic process

$$
\Delta \theta_{t}=\underbrace{\mu\left(\theta_{t}, t\right) \Delta t}_{\text {Deterministic Growth }}+\underbrace{\sigma\left(\theta_{t}, t\right) \Delta Z_{t}}_{\text {Smoothly evolving un certainty }}+\underbrace{\kappa d q}_{\text {Discrete innovations }}
$$

where $\mu$ is the expected growth rate of $\theta, \sigma$ is its instantaneous volatility, ? $\mathrm{Z}_{\mathrm{t}}$ is standard Normal distributed, $\mathrm{d} q$ is a Poisson process with intensity parameter $\lambda$ and $\kappa$ is the random percentage jump amplitude conditional on the Poisson event occurring (Merton, 1976).

Changes in the quality-adjusted price may reflect unpredictable shifts in consumer preferences or incremental technical change. For example, an increase in oil prices would lead 
consumers to prefer cars which save in fuel consumption. As long as these changes are fairly smooth, it seems reasonable to capture this uncertainty in volatility. This term represents the uncertainty in the environment around the local peak.

Other changes may be more radical and appear as discontinuous Poisson jumps, such as the arrival of new organizational innovations and is a measure of the granularity of the environment. These changes would appear as a sudden jump in price to a firm.

The quality-adjusted price approach to building a valuation model face potential problems. The argument hinges on the premise that the risk profile of the value of the innovation is spanned by quality adjusted prices. However, the quality adjusted price is derived from a model of the industry pricing behavior and can suffer from "modeling error." Furthermore, the quality adjusted price may not perfectly track the value of the innovation and introduce a "tracking error." This error is akin to basis risk in commodity markets where the price of a commodity is specific to its location. Finally, not being a security price, the quality adjusted price can embed a convenience value that is not easily observed or estimated. For the arbitragebased valuation approach to work, the error components must be independent of each other and have no systematic risk. Hence, expert opinion may provide a superior method to form probability distributions of possible future market conditions for the new business in radically new landscapes.

\section{Looking Inside the Firm: Capability Sets}

Even if two firms are competing in the same industry and market, movement in prices of the strategic asset influences differently their value because of the relationship between the capabilities of the firm and the profit opportunities. To describe this formally, we make use of 
the notion of distance -that we showed to be a common assumption in strategy, organizational ecology, and complex systems- between discrete combinations of technology and organizational elements that define a capability. We develop first the notion of a capability set and then define the profit function of a firm in relation to its set of organizational and technological practices.

For convenience, we consider the case of an automobile producer choosing to say within the current set of mass production or switching to new high performance combinations called lean production. (See MacDuffie, 1996) A firm has the set of capabilities $\boldsymbol{c}$, where $\boldsymbol{c} \in \boldsymbol{C}$ is the set of all feasible capabilities. In our case, $\boldsymbol{C}$ contains "mass" and "lean" production families with their associated organizational structures. Each family of production techniques can contain many distinct technologies. They are, however, coupled with the same organizational structure. Hence, a technology family refers to all technologies that can be operated within a single organization..

Suppose the firm is currently employing technology in the "mass" production family, i.e., $c_{m}^{j} \in \boldsymbol{c}_{\boldsymbol{m}} \in \boldsymbol{C}$. The firm's problem is to decide what capabilities it should use in the current period. Specifically, its choices are (a) continue using $c_{m}^{i}$ (b) continue in the same family but make incremental technological improvements by employing a better mass production technique, $c_{m}^{i}$, or (c) make discontinuous organizational switch and employ lean production technique, $c_{l}^{k}$. Choices a and b reflect 'as is' evaluations; only c involves a 'could be' alternative. We capture the idea of inertia through the reorganizing costs incurred by switching from one capability to another, be it from mass into lean, or conventional pharmaceutics to biotechnology. We denote these large organizational costs of switching as $\Delta_{i j}$. For example, the cost of switching from $\mathbf{c}_{n}$ (mass production) to $\mathbf{c}_{l}$ (lean production) can be denoted as $\Delta_{m l}$. In practice, switching between 
capabilities will consume time, as Dirickx and Cool (1989) note. Our model assumes that there is an inverse monotonic relationship between cost of switching and the time taken to switch.

Hence, a switch that takes more time will be represented by a higher switching costs.

Within an organizational capability, switching costs between modules (in the sense of Baldwin and Clark) are small, but not insignificant. At the same time, continuing within the same family enables the firm to capitalize on local learning effects. If the firm continues in $c_{m}^{i}$ or moves to a better mass technique $c_{m}^{j}$ then it will subsequently learn by doing. However, switching from the $\mathrm{i}^{\text {th }}$ to the $\mathrm{j}^{\text {th }}$ technology may still incur technological costs. We define the local learning benefits in mass production as $-\delta_{\mathrm{mm}}$ and technological switching costs $\delta_{\mathrm{ii}}$.

To summarize the magnitude of switching costs between all combinations of capabilities and technologies, we denote the cost of switching from $c_{m}^{i}$ capability to $c_{l}^{j}$ will be $\delta_{m l}^{i j}=\underbrace{T_{i j}}_{\text {Technological change }}+\underbrace{\Omega_{m l}}_{\text {Organizational learning }}$ where
$T_{i j}=\left\{\begin{array}{cl}\overbrace{\delta_{i j}^{\text {technological cost }}} & \text { if } i \neq j \\ \underbrace{-\delta_{i i}}_{\text {technological learning }} & \text { if } i=j\end{array}\right.$
$\Omega_{i j}=\left\{\begin{array}{cl}\overbrace{\overbrace{m l}^{\text {organizational cost }}}^{\overbrace{o_{m l}}^{-o_{m m}}} & \text { if } \mathrm{m} \neq l \\ \underbrace{}_{\text {organizational learning }} & \text { if } \mathrm{m}=l\end{array}\right.$

We can now write down the firm's objective. Each set of capabilities $\boldsymbol{c}_{\boldsymbol{m}}^{\boldsymbol{i}}$ has an accompanying profit function that is obtained by solving the usual profit maximization problem:

$$
\Pi\left(\theta, c_{m}^{i}\right)=\max _{y \in c_{m}^{i}} \theta \cdot y
$$

where $\theta$ is a vector of quality-adjusted input and output prices and $y$ is the vector of input and output levels that are determined by the capability set. This simple expression indicates that the 
firm's ability to choose the best strategy is contingent on its organizational resources.

\section{Dynamic Valuation of the Critical Capability Set}

When future values of $\theta$ evolve stochastically, the current decision influences all future decisions as well. The decision by a mass producer of cars to invest in flexible manufacturing using lean production runs the risk that the American market suddenly decides to buy large recreational vehicles made best by standard mass production techniques. But now they face the problem that they are invested in lean manufacturing, and cannot easily switch back. The tight coupling of organization and technology is essential to understanding why capabilities radically changes the understanding of strategy as not only the choice of entering markets, but also as the selection of competence.

The way to analyze fully the implications of inertia is to write out explicitly the problem over time. To do this, we no longer work directly with profit functions, but instead with a value function. While technically this problem is often hard to solve, its formulation is both intuitive and insightful. At a point in time (t), this formulation treats the present value of all future benefits given optimal future behavior, as represented by the value function $V\left(\theta_{t}, c_{m}^{i}\right)$. The value function is the solution of the well-known Bellman equation:

$V\left(\theta_{\mathrm{t}}, c_{m}^{i}\right)=\max _{c_{l}^{j}}\left[\left(\Pi\left(\theta_{\mathrm{t}}, c_{l}^{j}\right)-\delta_{m l}^{i j}\right)+\rho E_{t}\left[V\left(\theta_{\mathrm{t}+1}, c_{l}^{j}\right)\right]\right]$

where $c_{\boldsymbol{m}}^{i}$, is the current capability $c_{\ell}^{j}$ chosen from the set of feasible technologies and organizations at time $t+1$. This formulation is Winter's optimal control suggestion that includes organizational knowledge, or capabilities, as a state variable.

The Bellman Equation has an intuitively appealing formulation, for it directly evaluates the exploitation the choice of current capabilities (the first term in brackets) with the value of 
persisting or switching in the future (the second term). This equation indicates that in each period the producer contemplates switching into a new capability. If it chooses capability $c_{l}^{j}$, it realizes benefits of $\Pi\left(\theta_{t}, c_{l}^{j}\right)$, but pays switching costs of $\delta_{m l}^{i j}$, and then arrives at the following period with value function $V\left(\theta_{t+1}, c_{m}^{j}\right)$. This value depends on the capability chosen, $c_{l}^{j}$, as well as on the value of the state variable next period, $\theta_{t+1}$. Because still $\theta_{t+1}$ unknown at time $t$, we take expectations; we also discount at rate $\rho$. (See Pindyck, 1991, and Kulatilaka and Marcus, 1994, for a more explicit treatment of systematic risk.)

In each period, the producer chooses the capability $c_{l}^{j}$ that maximizes the value of the project. This choice can be interpreted as defining the dynamic capability as $c^{* *}=\underset{c_{l}^{j}}{\operatorname{argmax}}\left[\left(\Pi\left(\theta_{\mathrm{t}}, c_{l}^{j}\right)-\delta_{m l}^{i j}\right)+\rho E_{t}\left[V\left(\theta_{\mathrm{t}+1}, c_{l}^{j}\right)\right]\right.$

In the absence of switching costs, the solution to this optimization problem is simple: choose in each period the capability $c_{l}^{j}$ that maximizes $\Pi\left(\theta_{t}, c_{l}^{j}\right)$ in that period. This is the static critical capability discussed earlier. However, the presence of switching costs makes a forward-looking analysis necessary. In the case of costly reorganization, the probability distribution of future prices affects the current choice of technology and organization.

This definition of a dynamic capability defines our reinterpretation of a 'core competence.' Core competence is the capability set (i.e. combination of organization and technology elements) that permits the firm to choose dynamically the optimal strategy for a given price realization of the strategic factor.

\section{Hysteresis and Inertia:}

With the above concepts, we can now analyze more fully the hysteresis band first given in 
figure 1. Hysteresis is a critical concept, because it shows that inertia need not be the consequence of myopia but is itself sensitive to environmental turbulence and to a firm's competence. A more competent firm is, ironically, more subject to inertia.

The band between the switching costs is underestimated by comparing single-period breakeven profits, net of switching costs, under the two capabilities. Because of the possibility that $\theta$ may revert back to previous values (e.g. due to a sudden drop in oil prices favoring gasguzzling cars), the firm persists in its current mode and waits to see how prices evolve in the

future. At some point, however, $\theta$ takes on values that justify not only the one-time switching costs but also the probability-weighted costs attached to switching back. If a firm is unable to choose the optimal response, these conditions lead to a competency trap that is expressed by a hysteresis band. In figure 2, the profit functions for two capability sets and the resulting hysteresis band is graphed.

\section{Competency Traps and Learning to learn}

Due the benefits of learning by doing, simply exploiting current capabilities leads to cumulative and incremental improvement. In effect, the profit function can be described as shifting outward over time. By staying in its current activities, the firm becomes increasingly more competent. Techniques of mass production are expressed in well-understood routines that couple technology and people through known organizing principles of work.

The danger remains, of course, that $\theta$ will suddenly jump to a range or cross a critical threshold in which the firm's competence is no longer profitable. In a sense, its accumulated learning in the old techniques is a 'competency trap.' (See the discussion in March, 1991.) Yet, as a consequence, by improving in mass production, it is less attractive to change organizational 
capabilities. Hence a firm might rationally preserve its way of doing things, because it has become so good at doing the (now) wrong thing. Dougherty (1995) has labeled this "core incompetence." Exploitation of current knowledge drives learning by doing; the pitfall is that this learning increases the rigidity of the firm.

To speed its transition to new techniques, the firm may decide proactively to allocate funding to exploration by experimenting with new techniques. This diversion of resources slows down its accumulation of learning with the current technology. At the same time, it increases the value of the option to switch to new capabilities by lowering the costs of switching. To characterize this wider menu of choices, figure 3 depicts the decision of a firm that has accumulated a particular breadth of knowledge in the current production techniques, as well as in learning derived from experiments with new methods. (We can think of these experiments as 'joint ventures', such as the Nummi venture between General Motors and Toyota).

The net effects of learning are ambiguous and depend upon the rate by which new knowledge is gained through learning by doing relative to experimentation. In figure 4, this comparison is graphed by showing the upward change in profit functions over time due to these two learning effects. By construction, we show the gains to experimentation dominating learning by doing. Thus, while it is a truism that firms need to balance exploitation and exploration, the possibility for local learning may drive out distant search (Levinthal and March, 1993).

There is a more important insight provided by the investments in exploration, namely, that the literature on innovation over-emphasizes the difficulty posed by discontinuous change. In more contemporary parlance, the prospects of successful radical change are viewed as poor, because of the chance of jumping from one performance peak to a distant peak is considered as 
improbable. But exploratory investments permit the building of ridges between peaks. By exploring the current assets that can be recombined and coupled with new ones, a firm is able to reduce the risks of falsely choosing new capabilities. Through recombination, exploration reduces the organizational costs to successfully adopt radical change in its capabilities.

\section{Discussion: How Good a Heuristic?}

Real option theory provides complex heuristics to apply, though there are reasonable ways to simplify the application (Bowman and Moskowitz, 1997). Equally important is that real options heuristic carries the danger of negative transfer to inappropriate situations. A particularly troubling complication for real options analysis is the explicit consideration of competitive interactions and positioning. Competitive interactions endogenize the dynamics of the external market price. The valuation of a strategic option requires an identification of a market price by which to derive the replicate the underlying asset. In financial markets, this price is easily given by stock or future prices. An important, and reasonable assumption, is that exercising the option does not influence the value of the replicating portfolio.

This assumption does not hold always for real options for two reasons. First, by exercising an option to enter a market, a firm often influences prices through increasing supply. Second, by entering (or exiting) a market, competitors will alter their behavior. As a result, the market price is endogenous to the decision whether to exercise the option.

This problem is partly resolved by recognizing that the value of theta reflects the assessment on entry. But this assumption hardly provides insight into the identity of possible entrants and their strategic behavior. A structural approach is explicit regarding the nature of future competition. Kulatilaka and Perotti (1998) follow this approach by evaluating the decision 
to launch a new technology in the context of different conjectures about market structure. This solution marries the industry structure analysis to core competence, but through the stipulation that the analysis is forward-looking rather than focused on current market structure.

\section{Conclusions}

Real option analysis provides the theoretical foundations to the use of heuristics for deriving capabilities. Through conditioning an understanding of competence in relation to a market test (e.g. Barney's notion of a strategic factor market), it identifies the coupling of organization and technology as the leading explanation for the irreversibility of investments in capabilities. In a narrow sense, it faults discounted cash flow analysis as the principal tool of understanding the value of a firm. But more profoundly, the recognition that the coupling of people and technology is a source of option value challenges simplistic notions of firms as "pure asset plays." In this respect, it strengthens the argument that a firm's most enduring advantage lies in its human resources (Pfeffer, 1994).

Ironically, then, the derivation of the option value from the embedded knowledge in organizational assets deflects a purely financial evaluation of the firm. Because organizations consist of coupled systems, the value of the firm is not reflected in the present value of its constituent parts, but in the combinative potential of deploying these capabilities for innovation in existing markets or for addressing new markets. It suggests that firms are dynamic systems consisting of the complex coupling of technology and people through organizational design. The paradoxical conclusion to the sustained application of financial modeling to firms is that in the end, the fundamental basis of the value of the firm is its organizational capability to exploit current assets and explore future opportunities. 
The recent efforts in organizational theory to embrace complex systems analysis underscores the importance of understanding distance in capabilities in conjunction with the volatility of the environment. An appropriate heuristic arising out of complex systems is to understand landscape contours as representing market expectations of the value of discrete organizational capabilities. An options approach indicates that firms construct exploratory ridges between peaks to hedge against adverse changes in the landscape. But to understand the direction of exploration, it is necessary not only to know distances and locations of peaks, it is also important to know their heights, that is, their value. Bridging market valuations and inert capabilities answers the long sought goal in organizational theory: to reconcile theories of closed and open organizational systems. 


\section{References}

Amram, Martha and Nalin Kulatilaka, 1999a, Real Options: Managing Strategic Investments in an Uncertain World, Harvard Business School Press.

Argyris, Chris and Donald Schon, 1978, Organizational Learning, Reading, MA: AddisonWesley.

Baldwin, Carliss, and Kim Clark, 1992, "Capabilities and Capital Investment: New Perspectives on Capital Budgeting." Journal of Applied Corporate Finance, 5: 67-82.

Baldwin, Carliss, and Kim Clark, 1994, "Capital Budgeting Systems and Capabilities

Investments in U.S. Companies after World War II,” Business History Review, 68(1): 73-109.

Baldwin, Carliss, and Kim Clark, 1999, Design Rules: The Power of Modularity, MIT Press.

Barney, Jay, 1986, "Strategic Factor Markets: Expectations, Luck, and Business Strategy," Management Science, 32(10): 1231-1241.

Black, F. and M. Scholes, 1973, 'The pricing of options and corporate liabilities, Journal of Political Economy, No. 81, pp. 637-659.

Bowman, Edward, 1963, "Consistency and Optimality in Managerial Decision Making," Management Science, 9:310-321.

Bowman, Edward, 1995, "Strategy History: Through Different Mirrors," Advances in Strategic Management, 11: 25-45.

Bowman, Edward and Gary Moskowitz, 1997, "The Use of Options Analysis in Strategic Decision Making," Reginald H. Jones Center Working Paper.

Boyer, Robert, Bernard Chavance, and Olivier Godard (eds), 1991, Les Figures de l'irréversibilité en Économie, Paris: EHESS.

Brown, Shona and Kathleen Eisenhardt, Competing on the Edge: Strategies as Structured Chaos, Boston: Harvard Business School Press.

Cohen, Michael, 1999, "Commentary on the Organization Science Special Issue on Complexity," Organization Science, 10: 373-376.

Cohen, Michael and Paul Bacdayan, 1994, "Organizational Routines are Stored as Procedural Memory: Evidence from Laboratory Study," Organization Science, 5: 554-568.

Dierickx, Ingemar and Karel Cool, 1989, "Asset Stock Accumulation and the Sustainability of Competitive Advantage,” Management Science, 35: 1504-11. 
Dixit, Avinash and Robert Pindyck, 1994, Investment Under Uncertainty, Princeton: Princeton University Press.

Dosi, Giovanni and Bruce Kogut, 1993, "National Specificities and the Context of Change: The Coevolution of Organization and Technology," in Country Competitiveness: Technology and the Organizing of Work, ed. B. Kogut, New York: Oxford University Press.

Dougherty, Deborah, 1995, "Managing Your Core Incompetencies for Innovation," Entrepreneurship, Theory, and Practice, 19: 113-135.

Georgescu-Roegen, Nicholas, 1971, The Entropy Laws and Economic Progress, Cambridge, MA: Harvard University.

Hamel, Gary and Prahalad, C.K., 1994, Competing for the Future: Breakthrough Strategies, Boston: Harvard Business School Press.

Hannan, Michael and John Freeman, 1977, "The Population Ecology of Organizations," American Journal of Sociology, 82: 929-964.

Hannan, Michael and John Freeman, 1984, "Structural Inertia and Organizational Change," American Sociological Review, 49: 149-164.

Hedlund, Gunnar and Dag Rolander, 1990, "Action in Heterarchies: New Approaches to Managing the MNC," in Managing the Global Firm, edited by Christopher A. Bartlett, Yves Doz, and Gunnar Hedlund, London ; New York : Routledge.

Henderson, Rebecca, 1993, "Underinvestment and Incompetence as Responses to Radical Innovation: Evidence from the Photolithographic Alignment Equipment Industry," Rand Journal, 24: 248-270.

Henderson, Rebecca and Kim Clark, 1990, "Architectural Innovation: The Reconfiguration of Existing Product Technologies and the Failure of Established Firms," Administrative Science Quarterly, 35: 9-30.

Henry, Claude, 1974, "Investment Decisions under Uncertainty: the "Irreversibility Effect," American Economic Review, 64: 1006-1012.

Hull, John C., 1997, Options, Futures, and Other Derivatives, (3rd Edition), Prentice-Hall, New Jersey.

Kauffman, Stuart, 1993, The Origins of Order: Self Organization and Selection in Evolution, New York: Oxford University Press. 
Kim, Dong Jae and Bruce Kogut, 1996, “Technological Platforms and Diversification," Organization Science, 7: 283-301.

Kogut, Bruce and Nalin Kulatilaka, 1992, (revised 1994) "What is a Critical Capability?," Reginald H. Jones Center Working Paper, Wharton School.

Kogut, Bruce and Nalin Kulatilaka, 1994a, "Options Thinking and Platform Investments: Investing in Opportunity," California Management Review, 36: 52-71.

Kogut, Bruce and Nalin Kulatilaka, 1994b, "Operating Flexibility, Global Manufacturing, and the Option Value of Multinationality,” Management Science, 40: 123-139.

Kulatilaka, Nalin and Alan J. Marcus, 1994, "Hedging Foreign Project Risk," Journal of International Financial Management and Accounting, 5(2): 142-156.

Kulatilaka, Nalin and Enrico Perotti, 1998, "Strategic Growth Options," Management Science, 1021-1031.

Kunreuther, Howard, 1969, "Extensions of Bowman's Theory on Managerial Decision-Making," Management Science, 16: B415-439.

Levinthal, Daniel, 1997, “Adaptation on Rugged Landscapes,” Management Science, 43: 934950.

Levinthal, Daniel and James March, 1993, "The Myopia of Learning," Strategic Management Journal, 14: 95-112.

Lewin, Arie and Henk Volderba, 1999, "Prolegomena on Co-evolution: A Framework for on Research on Strategy and New Organizational Forms," 10:519-534.

Lincoln, James, 1993, "Comparison of Japanese and US Organizational Structures," in Country Competitiveness: Technology and the Organizing of Work, ed. B. Kogut, New York: Oxford University Press.

MacDuffie, John Paul, 1996, "Human Resource Bundles and Manufacturing Performance: Flexible Production Systems in the World Auto Industry," Industrial and Labor Relations Review.

Mansfield, Edward, 1988, "Speed and Cost of Industrial Innovation in Japan and United States," Management Science, 34: 1157-1168.

March, James, 1991, "Exploration and Exploitation in Organizational Learning," Organization Science, 2: 71-87.

March, James and Herbert Simon, 1958, Organizations, New York: Wiley. 
McDonald, Robert, and Daniel Siegel, 1984, "Option Pricing When the Underlying Asset Earns a Below-Equilibrium Rate of Return: A Note,” Journal of Finance , 261-265.

McKelvey, Bill, 1999, "Avoiding Complexity Catastrophe in Coevolutionary Pockets: Strategies for Rugged Landscapes," Organization Science, 10: 294-321.

Merton, Robert C., 1976, "Option Pricing When Underlying Stock Returns are Discontinuous," Journal of Financial Economics, 3:125:144.

Midler, Christopher, 1993, L'auto qui n'existe pas. Management des projets et transformation de l'enterprise, Paris: InterEditions.

Milgrom, Paul and John Roberts, 1990, "The Economics of Modern Manufacturing: Technology, Strategy, and Organization, American Economic Review, 80: 511-528.

Minsky, Marvin, 1985, The Society of Mind, New York: Simon and Schuster.

Nelson, Richard R. and Sidney G. Winter, 1982, An Evolutionary Theory of Economic Change, Cambridge, MA: Harvard University Press.

Pfeffer, Jeffrey, 1994, Competitive Advantage through People, Boston: Harvard Business School Press.

Pfeffer, Jeffrey and Gerald Salancik, 1978, The External Control of Organizations: A Resource Dependence Perspective, New York: Harper and Row.

Pindyck, Robert S, 1991, "Irreversibility, Uncertainty, and Investment," Journal of Economic Literature, 29(3): 1110-1148.

Prigogine, Ilya and Isabelle Stengers, 1984, Order Out of Chaos. Man's New Dialogue with Nature, Bantam Book: New York.

Scherer, F.M., 1967, "Research and Development Resource Allocation under Rivalry," Quarterly Journal of Economics, 81: 359-94.

Scott, W. Richard, 1995, Institutions and Organizations, Thousand Oaks: Sage.

Selznick, Philip, 1957, Leadership in Administration, A Sociological Interpretation, Evanston, Ill.: Row, Peterson.

Simon, Herbert, 1969, The Sciences of the Artificial, Cambridge: MIT Press, First Printing (Seventh Printing 1992). 
Szulanski, Gabriel, 1995, Unpacking Stickiness: An Empirical Investigation of the Barriers to Transfer Best Practice Inside the Firm," Academy of Management Best Paper Proceedings: 437-441.

Teece, David, Gary Pisano, and Amy Shuen, 1997, "Dynamic Capabilities and Strategic Management," Strategic Management Journal, 18: 509-534.

Thompson, James D., 1967, Organizations in Action: Social Science Bases of Administrative Theory, New York: McGraw Hill.

Tuma, Nancy Brandon and Michael T. Hannan, 1984, Social Dynamics: Models and Methods, New York: Academic Press.

Tushman, Michael and Philip Anderson, 1986, “Technological Discontinuities and Organizational Environments” Administrative Science Quarterly, 31: 439-465.

Tushman, Michael and Charles O'Reilly, 1997, Winning Through Innovation. A Practical Guide to Leading Organizational Change and Renewal, Boston: Harvard Business School Press.

Winter, Sidney, 1987, "Knowledge and Competence as Strategic Assets," in D. Teece, ed., The Competitive Challenge -- Strategies for Industrial Innovation and Renewal, Cambridge, MA: Ballinger, pp. 159-184.

Zander, Udo and Bruce Kogut, 1995, Knowledge and the Speed of the Transfer and Imitation of Organizational Capabilities: An Empirical Test," Organization Science, 6: 76-92. 


\section{Figure 1}

The Implications of Hysterisis on the Choice of New Techniques

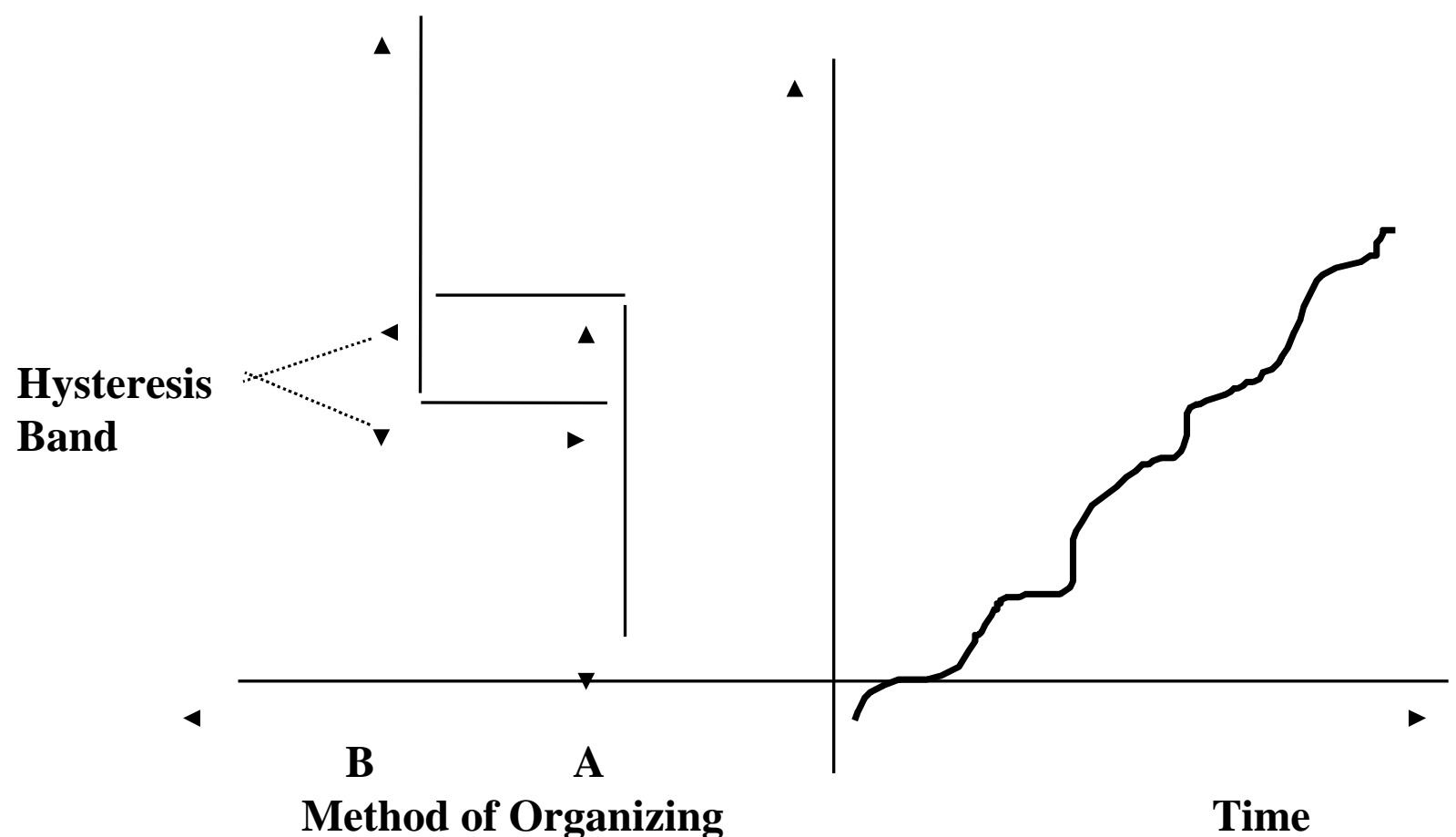

A: $\quad$ Mass Production

B: $\quad$ Toyotaism 
Figure 2

\section{Choice of Capability Set: "Static Case"}

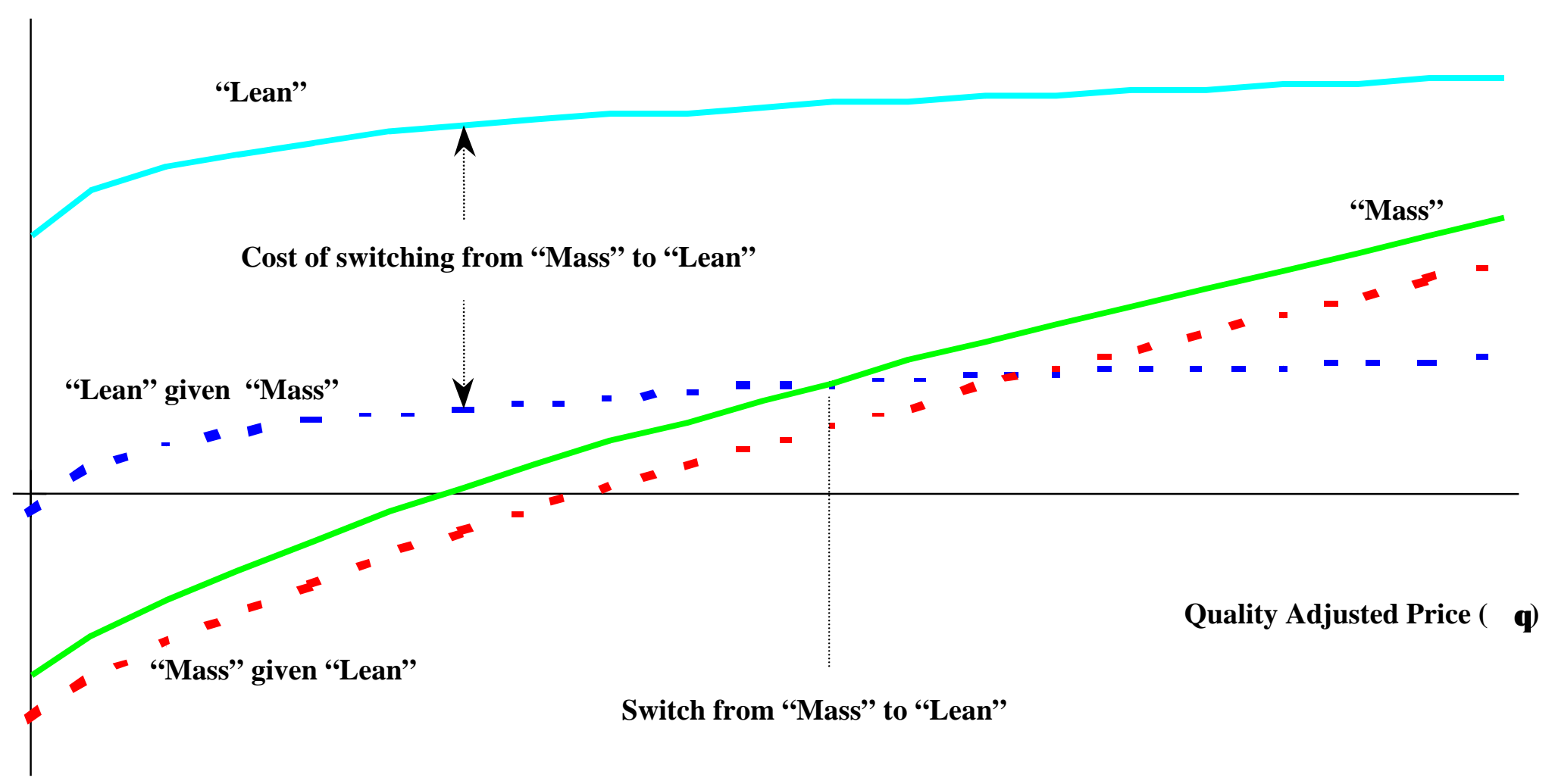




\section{Figure 3}

\section{Static and Dynamic Hysteresis}

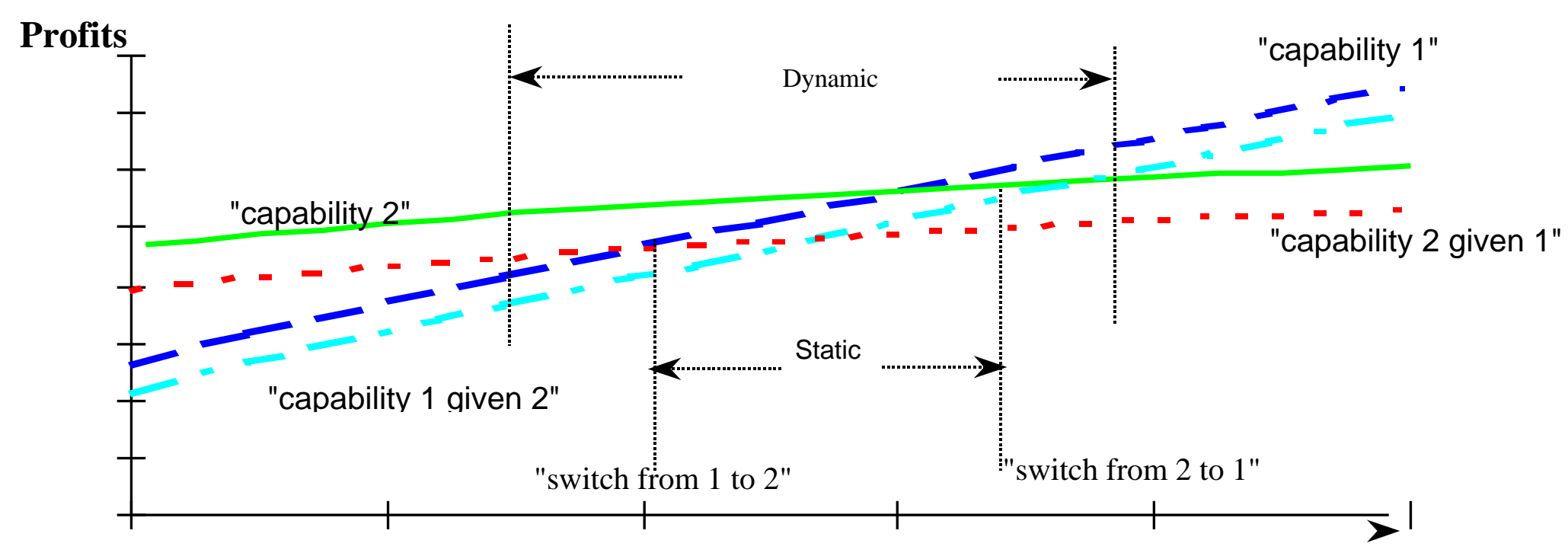

Quality Adjusted Price ( $\theta$ ) 


\section{Figure 4}

\section{Expanded Capability Sets}

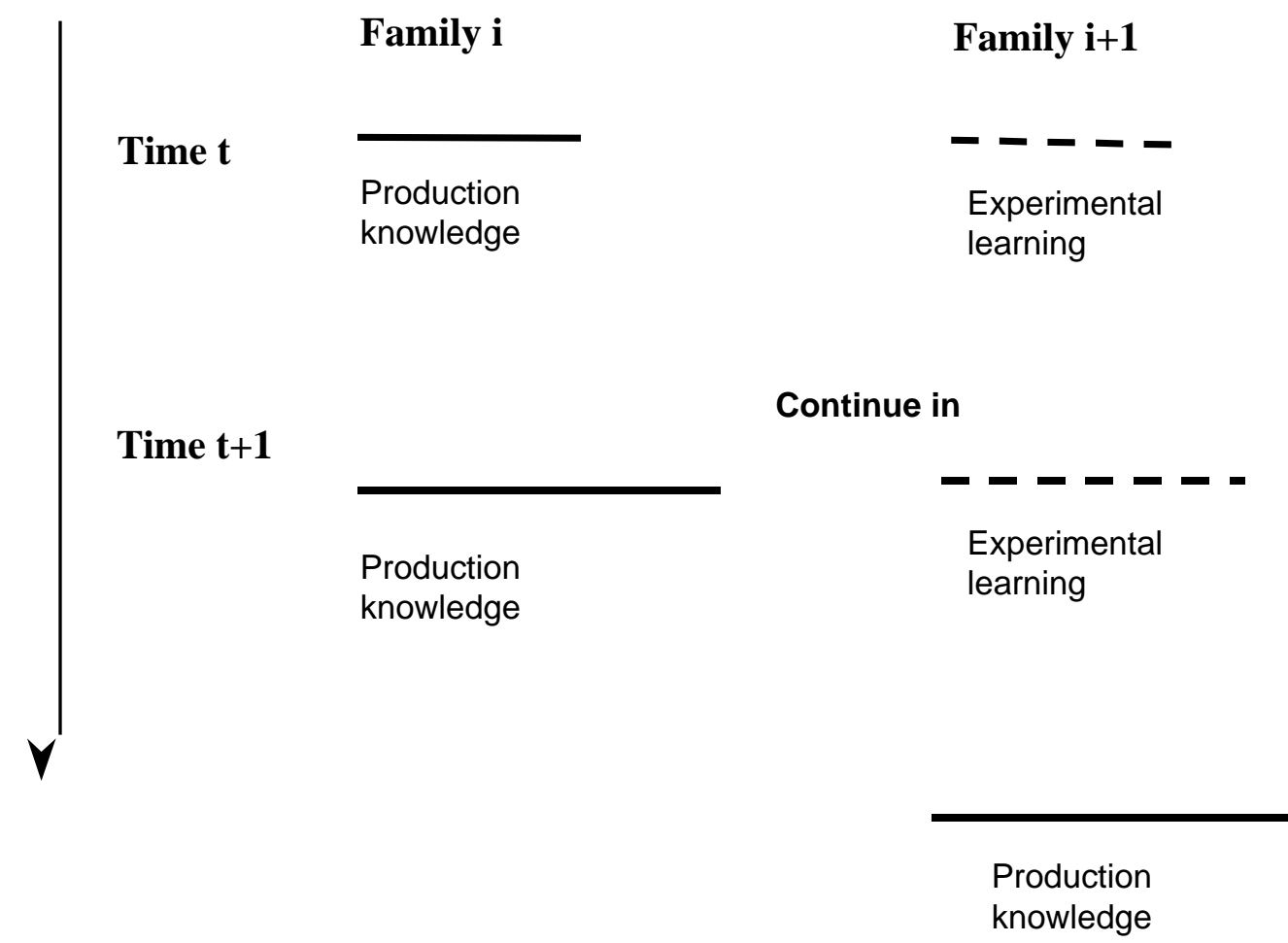

Family i+2

Switch to

----
Experimental
learning 